\title{
Patient Satisfaction with Services in King Abdulaziz University Dental Hospital
}

\author{
Ghada H. Naguib ${ }^{1,2}$, DSc, MHPE, Mohamed T. Hamed ${ }^{3,4}$, MPH, MHPE, \\ Abeer M. Alnowaiser ${ }^{5}$, MHPE, PhD, Amal M. Sindi ${ }^{6}, \mathrm{MSc}, \mathrm{PhD}$, and \\ Nadia Al-Hazmi ${ }^{7}$, BDS, PhD
}

Department of ${ }^{1}$ Conservative Dental Sciences, ${ }^{3}$ Oral \& Maxillofacial Rehabilitation ${ }^{5}$ Preventive Dental Sciences, ${ }^{6}$ Oral Basic and Diagnostic Science, and ${ }^{7}$ Oral Biology Faculty of Dentistry, King Abdulaziz University, Jeddah, Saudi Arabia

Department of ${ }^{2}$ Oral Biology and ${ }^{4}$ Prosthodontic Faculty of Dentistry, Cairo University, Cairo, Egypt

\section{Correspondence}

Dr. Nadia Al-Hazmi

P.O. Box 80498, Jeddah 21589

e.M: nalhazmi@kau.edu.sa

Submission: 05 Jan. 2016

Accepted: $\quad 16$ Feb. 2016

\section{Citation}

Naguib GH, Hamed MT, Alnowaiser AM, Sindi AM, Al-Hamzi N. Patient satisfaction with services in King Abdulaziz University Dental Hospital. JKAU Med Sci 2016; 23 (2): 21-28. DOI: 10.4197/Med. 23.2.3

\begin{abstract}
Patient satisfaction levels in any health institute are a key performance indicator of quality health care. We constructeda 36-item questionnaire and distributed it over a three-month period (from February to April 2014) to 301 patients treated in various departmental clinics at King AbdulazizUniversity Dental Hospital. The surveyaddressed satisfaction with facilities, helpfulness of the staff, progress of treatment, quality of care and treatment with dignity and compassion. Patients were overall satisfied with the treatment received (84.1\%), with particular satisfaction for doctors and faculty supervisors being courteous (73.4\%, and 61.0\%, respectively), and addressing their concern (54.3\% and $60.0 \%$, respectively). Dissatisfaction was found with the patient relations' attitude (48.2\%) and professionalism (49.6\%), and the majority of patients claimed to be very unsatisfied with the referral system (69.0\%) and the difficulty in contacting the clinics (72.0\%). The results of the present study revealed that King Abdulaziz University Dental Hospital provides quality dental services to its patients and there is an overall high rate of patient satisfaction for the treatment and services rendered by the institute. However there are still issues and some concerns such as patient relation communication skills and referral system professionalism that have to be addressed in order to improve the patient experience.
\end{abstract}

\section{Keywords}

Dental; Hospital; Patients; Satisfaction; Services; Quality 


\section{Introduction}

$P$ atient satisfaction is an important indicator in the assessment of the quality of healthcare services ${ }^{[1-6]}$. However, it is not only affected by the quality of the health services provided but also by the capability of the health personnel to properly communicate with the patients and by the patient's expectations of a health care setting ${ }^{[7]}$. Patient satisfaction surveys are being used with increasing frequency in the evaluation of medical care worldwide ${ }^{[4,7-11]}$. They have been used for assessing the quality of care in the hospital setting, in international comparisons and to explore the link between treatment satisfaction and adherence, compliance, and persistence $\mathrm{e}^{[2,12,13]}$. These surveys have also been used by dental health care providers worldwide in order to respond to patients' needs and to improve the quality of the services they provide ${ }^{[2,14-16]}$.

The need to improve the quality of healthcare in Saudi Arabia has increased drastically in the last few years principally due to the $2.7 \%$ annual increase in the Saudi population ${ }^{[17]}$. In order to provide sufficient care across each of its provinces, Saudi Arabia's 2013 budget included funds for 19 new hospitals, on top of the 102 that were currently being built. However there were concerns that the speed of healthcare capacity expansion could compromise the quality of healthcare services. Experts considered accreditation to be the gold standard in healthcare and that it could contribute to the maintenance and improvement of quality, therefore influencing healthcare outcomes positively.

Patient satisfaction is an important factor that has to be considered in every dental hospital or health institution. Several studies were done in Saudi Arabia to assess patient satisfaction in Riyadh, Madinah and Qassim. ${ }^{[17-25,27]}$ However, effective healthcare relies significantly on the co-contribution of the patient to the service delivery process. Satisfaction not only relies on the dental treatment but also on the collaboration of the hospital team. This team includes dentists, assistants, technicians as well as receptionists. They should all work together having one goal that is to gain the trust of patients, as this will reflect in patients' readiness to follow up with the treatment and their compliance to take the medicines.

There is a scarcity of evidence associating patient satisfaction with objectively measured indicators of care quality or improved outcomes in Saudi Arabia especially in dentistry. This gap and the continued pursuit of excellence prompted the need to determine the level of patient satisfaction in King Abdulaziz University Dental Hospital (KAUDH). Hence, the purpose of this study was to assess the satisfaction of patients treated at KAUDH in order to improve the quality of services and meet with the patients' highest expectations.

\section{Materials and Methods}

A cross-sectional study was conducted at the dental clinics of the dental hospital from February to April 2014. These three months were chosen as representative of the busiest three months in terms of patient flow during the last five years. This calculation was achieved from retrospective analysis of dental records used. We cannot attribute this to seasonal variations as Jeddah is a city that maintains warm weather throughout the year; however, these are the months that have the least number of holidays (the Muslim holy festivities of Eid Al-Fitr and Eid Al-Adha fall during the summer months).

A simple random sampling technique was used; patient flow (number of patients seeking treatment in a particular area of the hospital) was analyzed on all sectors of KAUDH. The main division was: patients attending undergraduate clinics, faculty clinics and general practitioner (GP) clinics. A total number from KAUDH was obtained and the sampling was done as a ratio to the whole for every section to ensure the distribution remains representative. The Research Ethics Committee of the Faculty of Dentistry, at King Abdulaziz University, approved this study. The waiver of the informed consent process was approved on the basis of the questionnaire's being anonymous, optional, self-administered and containing no identifiers.

A self-administered revised questionnaire was used to assess patients' satisfaction with the dental service provided in the dental clinics of KAUDH. A questionnaire was designed from cues of questions used in previous results, and formulated in a manner that would help us better understand our patients' concerns and needs. In the long run, this will assist us with correcting any faults and strengthening our staff's skills in the necessary areas in order to provide optimal dental care services and gain patient satisfaction. The questionnaire has been approved by the Patient Care Quality Assurance Committee (PCQA) working in conjunction with the Commission on Dental Accreditation (CODA) ad-hoc committee striving to fulfill Standard 5 (Patient Care) of the report. The questionnaire was distributed by receptionists 
and dental interns to patients as they arrived for their appointment. The questionnaire was used to measure varying criteria affecting patients' satisfaction. In addition to the socio-demographic characteristics (age, gender and education), the questionnaire consisted of 7 sections based on empathy and responsiveness aspects: Patient-doctors interaction (5 items); patientfaculty supervisors interaction (5 items); patient-X-ray personnel interaction ( 3 items); patient-dental assistant interaction (2 items); patient-reception interaction ( 3 items); patient relations department efficiency ( 2 items); and clinic setup/environment (2 items). The questionnaire was drafted in both Arabic and English with a 5-point Likert response scale ranging from 1 (Strongly Disagree) to 5 (Strongly Agree). The 5-point scale was later transformed during data analysis to a 3 -point response scale ranging from 1 (Disagree) to 3 (Agree), with 2 corresponding to neutral as answers in strongly agree and strongly disagree were uncommon. Percentages of agreement on the seven disciplines of satisfaction were calculated. The mean percentages of satisfaction were calculated to estimate the overall ranking analysis of individual satisfaction disciplines.

\section{Statistical Analysis}

The data was coded and keyed into the Statistical Package for the Social Sciences software IBM SPSS Statistics for Windows, Version 22 (IBM Corp., Armonk, NY USA). Descriptive analysis followed by inferential statistics was done. Also chi-square $\left(X^{2}\right)$ test was performed to detect the degree of significance at $\mathrm{P}<$ 0.05 .

\section{Results}

Out of the 301 participants, the response rate was $99 \%$, 132 were males (44.3\%) and $166(55.7 \%)$ females, with $61.4 \%$ between the age range of $30-50$ years old. $40 \%$ of patients attended only high school and $39 \%$ received college education or higher (Table 1).

Overall, patients were satisfied with the treatment received $(84.1 \%)$. Satisfied patients were mostly females $(82 \%), \geq 40$ years $(53.0 \%)$ and with a high degree of education. There was insignificant difference in the satisfaction based on age $(p=0.9)$, gender $(p=$ 0.2 ) or education levels $(p=0.2)$ (Table 2 ).

Table 1. Socio-demographic data of participants.

\begin{tabular}{|l|l|c|c|}
\hline \multicolumn{2}{|l|}{ Variables } & $\begin{array}{c}\text { Count } \\
\mathbf{N}=298\end{array}$ & $\%$ \\
\hline \multirow{4}{*}{ Age } & $18-20$ years & 43 & $14.42 \%$ \\
\cline { 2 - 4 } & $21-29$ years & 72 & $24.16 \%$ \\
\cline { 2 - 4 } & $30-39$ years & 81 & $27.18 \%$ \\
\cline { 2 - 4 } & $\geq 40$ years & 102 & $34.22 \%$ \\
\hline \multirow{3}{*}{ Gender } & Male & 132 & $44.30 \%$ \\
\cline { 2 - 4 } & Female & 166 & $55.70 \%$ \\
\hline \multirow{3}{*}{ Education } & Less than High School & 64 & $21.47 \%$ \\
\cline { 2 - 4 } & High School & 118 & $39.59 \%$ \\
\cline { 2 - 4 } & College/ University or Higher & 116 & $38.92 \%$ \\
\hline \multirow{3}{*}{ Rate of satisfaction } & Agree & 148 & $49.66 \%$ \\
\cline { 2 - 4 } & Neutral & 103 & $34.56 \%$ \\
\cline { 2 - 4 } & Disagree & 47 & $15.77 \%$ \\
\hline
\end{tabular}

Table 2. Significance of demographics with rate of satisfaction.

\begin{tabular}{|c|c|c|c|c|c|}
\hline \multirow{2}{*}{\multicolumn{2}{|c|}{ Demographics }} & \multicolumn{3}{|c|}{ Rate your Satisfaction } & \multirow{2}{*}{ p-value } \\
\hline & & \multirow{2}{*}{$\begin{array}{c}\text { Agree } \\
21(48.83 \%)\end{array}$} & \multirow{2}{*}{$\begin{array}{c}\text { Neutral } \\
15(34.88 \%)\end{array}$} & \multirow{2}{*}{$\begin{array}{c}\text { Disagree } \\
7(16.27 \%)\end{array}$} & \\
\hline \multirow{4}{*}{ Age } & $18-20$ years $(n=43)$ & & & & \multirow{4}{*}{0.926} \\
\hline & $21-29$ years $(n=72)$ & $35(48.61 \%)$ & $27(37.50 \%)$ & $10(13.88 \%)$ & \\
\hline & $30-39$ years $(n=81)$ & $42(51.85 \%)$ & $27(33.33 \%)$ & $12(14.81 \%)$ & \\
\hline & $\geq 40$ years $(n=102)$ & $54(52.94 \%)$ & $30(29.41 \%)$ & $18(17.64 \%)$ & \\
\hline \multirow{2}{*}{ Gender } & Male $(n=103)$ & $62(46.96 \%)$ & $52(39.39 \%)$ & $18(13.60 \%)$ & \multirow{2}{*}{0.184} \\
\hline & Female $(n=166)$ & $86(51.80 \%)$ & $51(30.72 \%)$ & $29(17.46 \%)$ & \\
\hline \multirow{3}{*}{ Education } & Less than high school $(n=64)$ & $37(57.80 \%)$ & $14(21.80 \%)$ & $13(20.31 \%)$ & \multirow{3}{*}{0.166} \\
\hline & High school $(n=118)$ & $63(53.30 \%)$ & $42(35.50 \%)$ & $13(11.00 \%)$ & \\
\hline & College/ university or higher $(n=116)$ & $57(49.13 \%)$ & $42(36.20 \%)$ & $17(14.65 \%)$ & \\
\hline
\end{tabular}


Particular satisfaction was observed with regards to doctors being courteous (73.4\%), and explaining the procedure clearly (60.4\%). However patients had concerns with regards to doctors listening carefully (58.0\%), addressing their concerns (54.3\%) and performing procedures with gentleness (49.0\%). $(p<0.05)$. Patients were also satisfied with regards to faculty supervisors being courteous (61.0\%), addressing their concern (60.0\%) and interacting well with students (57.3\%). However, they had concerns about faculty supervisors listening carefully $(45.0 \%)$ and arriving in a timely fashion $(43.6 \%)(p<0.05)$. Patients were satisfied with the X-ray waiting time $(70.8 \%)$, with the $\mathrm{X}$-ray personnel being courteous and kind (51.8\%) and found the waiting times adequate
( $<20$ minutes) (Table 3). Patients were satisfied with the dental assistants' friendliness (68.4\%) and their positive interaction with the doctor $(47.5 \%)(p<0.05)$. While a low percentage of patients were satisfied with the receptionists' friendliness (34.8\%), knowledge $(47.6 \%)$, professionalism and behavior $(42.9 \%)$ and the comfort of the waiting room (38.5\%) (Table 3), they were unsatisfied with the Patient Relations office personnel's attitude (48.2\%) and professionalism $(49.6 \%)$. They were also unsatisfied with the long waiting time between appointments (56.0\%), amount of time needed to check in (60.0\%), and the majority of patients were very unsatisfied with the referral system $(69.0 \%)$ and method of contacting the clinics (72.0\%) (p $<0.05$ ) (Table 3).

Table 3. Significance of participants' satisfaction in different domains.

\begin{tabular}{|c|c|c|c|c|}
\hline & Agree & Neutral & Disagree & p-value \\
\hline \multicolumn{5}{|l|}{ Participants' satisfaction on doctors' interaction } \\
\hline Courteous and kind & $219(73.40 \%)$ & $61(20.40 \%)$ & $18(6.00 \%)$ & 0.05 \\
\hline Explained procedures clearly & $180(60.40 \%)$ & $90(30.20 \%)$ & $28(9.30 \%)$ & 0.05 \\
\hline Listened carefully & $173(58.00 \%)$ & $97(32.50 \%)$ & $28(9.30 \%)$ & 0.05 \\
\hline Addressed all my concerns & $162(54.30 \%)$ & $85(28.50 \%)$ & $51(17.10 \%)$ & 0.05 \\
\hline Performed procedures with gentleness & $146(48.90 \%)$ & $110(36.90 \%)$ & $42(14.00 \%)$ & 0.05 \\
\hline \multicolumn{5}{|l|}{ Participants'satisfaction on Faculty supervisors' interaction } \\
\hline Courteous and kind & $182(61.00 \%)$ & $105(35.00 \%)$ & $11(3.60 \%)$ & 0.05 \\
\hline Listened carefully & $134(44.90 \%)$ & $138(46.30 \%)$ & $26(8.70 \%)$ & 0.05 \\
\hline Addressed all my concerns & $179(60.00 \%) \backslash$ & $112(37.50 \%)$ & $7(2.30 \%)$ & 0.05 \\
\hline Arrived in timely fashion & $130(43.60 \%)$ & $124(41.60 \%)$ & $44(14.70 \%)$ & 0.05 \\
\hline Interacted well with students & $171(57.30 \%)$ & $110(36.90 \%)$ & $17(5.70 \%)$ & 0.05 \\
\hline \multicolumn{5}{|l|}{ Participants'satisfaction on X-ray procedure and X-ray personnel } \\
\hline Courteous and kind & $172(57.80 \%)$ & $91(30.50 \%)$ & $35(11.70 \%)$ & 0.05 \\
\hline Addressed all my concerns & $162(54.30 \%)$ & $71(23.80 \%)$ & $65(21.00 \%)$ & 0.05 \\
\hline Waiting time was adequate(0-20 min) & $211(70.80 \%)$ & $79(26.50 \%)$ & $8(2.60 \%)$ & 0.05 \\
\hline \multicolumn{5}{|l|}{ Participants' satisfaction on dental assistant personnel } \\
\hline Dental Assistant was friendly & $204(68.40 \%)$ & $87(29.10 \%)$ & $7(2.30 \%)$ & 0.05 \\
\hline Dental assistant interacted well with doctor & $142(47.50 \%)$ & $120(40.20 \%)$ & $36(12.00 \%)$ & 0.05 \\
\hline \multicolumn{5}{|l|}{ Satisfaction rates with the reception } \\
\hline Reception staff was friendly & $104(34.80 \%)$ & $132(44.20 \%)$ & $62(20.80 \%)$ & 0.05 \\
\hline Reception staff knowledgeable & $142(47.60 \%)$ & $103(34.50 \%)$ & $53(17.70 \%)$ & 0.05 \\
\hline Reception staff behaved in professional way & $128(42.90 \%)$ & $112(37.50 \%)$ & $58(19.40 \%)$ & 0.05 \\
\hline Waiting room was comfortable & $115(38.50 \%)$ & $101(33.80 \%)$ & $82(27.50 \%)$ & 0.05 \\
\hline \multicolumn{5}{|l|}{ Satisfaction rates with the patient relation office } \\
\hline Patient relation staff friendly & $37(12.00 \%)$ & $118(39.50 \%)$ & $143(48.20 \%)$ & 0.05 \\
\hline Patient relation staff behaved professionally & $25(8.30 \%)$ & $126(42.20 \%)$ & $147(49.60 \%)$ & 0.05 \\
\hline Long waiting time between appointments & $118(39.50 \%)$ & $14(4.60 \%)$ & $166(56.00 \%)$ & 0.05 \\
\hline Amount of time needed to check in & $109(36.50 \%)$ & $11(3.60 \%)$ & $178(6.00 \%)$ & 0.05 \\
\hline Amount of time waiting to see a doctor bothers you (Referral system) & $81(27.20 \%)$ & $12(4.00 \%)$ & $205(69.00 \%)$ & 0.05 \\
\hline Easy to contact a clinic & $74(24.80 \%)$ & $10(3.30 \%)$ & $214(72.00 \%)$ & 0.05 \\
\hline
\end{tabular}




\section{Discussion}

Measurement of patient satisfaction has been used lately to motivate changes in healthcare system ${ }^{[26]}$. Thus, it has received considerable attention from researchers where the patient is the focus. However many researchers found that patient satisfaction is directly correlated to patient's expectation, but not necessarily to clinical outcomes ${ }^{[9,14,20,27-29]}$.

The results of this study are in accordance with other Saudi studies ${ }^{[21-25]}$ : Patients were overall satisfied, with some degree of dissatisfaction varying from one area to the other.

In this study, the treatment that patients received with particular satisfaction with regards to doctors and faculty supervisors being courteous and addressing their concerns. This reflects well on the level of expertise of our faculty and undoubtedly provides a high level of patient trust in the services being rendered at our institute. However, our work highlighted a concern patients expressed in regards to the supervising faculty "listening carefully" to them and arriving on time to the sessions. This finding is particularly corroborated in the undergraduate clinics where the greatest complaint filed by students is the lateness of attendance of supervising faculty. This greatly disturbs the clinical process for both the students and the patients. While the first complaint may be explained by the large number of patients attending the institute, the second one cannot be defended in a rational manner. It provides an important finding that must be addressed by the hospital as a whole in order to improve the services. Communicating with patients is the cornerstone to quality patient service; therefore the hospital must use these findings to find a way to instill a clinical environment that is conductive to good doctor-patient communication. Several strategies may be adopted including increasing the number of staff, lengthening the clinical session time and providing a more accurate referral system.

As found in previous patient satisfaction studies ${ }^{[1,2,17-25,27]}$, our data shows that generally patients felt satisfied with dental auxiliaries (dental assistants, radiology technicians). In the past three years, KAUDH has hired a higher number of Arabic-speaking auxiliaries (as opposed to English-speaking foreign auxiliaries). This has been brought about both by a government initiative to boost jobs for Saudi nationals as well as the increasing number of dental auxiliary training programs. This was not seen in regards to receptionists and Patient Relation Office personnel, where we observed the lowest level of satisfaction on many parameters. A possible explanation is that personnel hired in these particular positions do not have any training in this field and are not assessed on their communication skills and experience during the hiring process. Many of them have completed only high-school level education and many have previous experience in non-medical environments. This warrants close examination as receptionists are strategic in the dental team. They not only provide the "face" of treatment as they are the very first individuals to meet the patient, but they also ensure proper flow of patients and provide referrals and a point of reference for patients seeking information. The same must be said of Patient Relation Office personnel. These individuals must exhibit a high level of skill in addressing patient concerns and represent the "customer relation" section in the hospital. This may be addressed by mandating courses prior to employment, as well as continuous staff development workshops to train them in communication skills, empathy and professionalism. Patient satisfaction was investigated by different medical and dental facilities ${ }^{[17-20]}$. In 1996 Al-Faris et al. ${ }^{[21]}$ evaluated patient satisfaction with different aspects of the Primary Health Care Centers (PHCC) services in Riyadh. While the satisfaction rate was $90 \%(n=466)$, dissatisfaction with certain areas had to be addressed. In 2001, Saeed et al. ${ }^{[22]}$ investigated consumers' satisfaction and correlated the finding with physicians' services provided by the Ministry of Health Primary Health Care Centers in Riyadh. They concluded that some physicians' service items needed corrective intervention and students and young patients appear to need more attention.

Services and treatment received at the Dental College in King Saud University were also investigated by Awliya ${ }^{[23]}$. The majority of the patients who responded (response rate of $82 \%)(n=560)$ were satisfied with the facilities, services and treatment received at the Dental College clinics of King Saud University. However, despite the positive results, establishing new strategies for improvements to patient care services were recommended. Aldebasi and Ahmed ${ }^{[24]}$ determined the level of the patient's satisfaction with the medical services and the delivery of those services. The response rate was 100\% $(n=500)$ with overall satisfaction of the medical services, but improvement was needed in the laboratory services in regards to providing enough time and better communication to the patients. The level of patient satisfaction on the dental services received from the 
King Khalid University College of Dentistry (KKU/CD) Clinics - Abha, Saudi Arabia was investigated by AlRefeidi et al. ${ }^{[25]}$. The response rate was $92.8 \%(n=836)$, and showed that patients were satisfied in the majority of areas investigated. There was a need for avoidance of delays before commencement of treatment and reducing patient's anxiety during treatment.

This questionnaire has provided baseline data to be used as a starting point to continuous development and improvement. Unsatisfied patients may cause a great deal of anxiety and stress among dental care providers but in order to deliver high quality oral healthcare it is necessary that patients' concerns are dealt with appropriately ${ }^{[29-31]}$. One of the fundamental beliefs in KAUDH is that when a patient is satisfied with the services provided they are more likely to adhere to the instructions given to them by their dentist regarding maintaining oral hygiene, taking their medications and returning for follow-ups. It is easier to serve patients when they are satisfied which also results in happier staff as well as patients. The quality of services provided has an influence on the patient's judgements of the dentist's skills as well as the strength of King Abdulaziz University Faculty of Dentistry's (KAUFD) education. Being a teaching hospital, we find it essential to enhance our curriculum in the ways necessary to give rise to a generation of exceptional dentists who can both meet as well as understand their patients' satisfaction. This study will assist us in improving the quality of care rendered and will aid the institute in staying competitive and relevant in the local community.

\section{Conclusion}

Our initial results revealed that overall KAUDH provides dental services that satisfy the majority of patients. However, some key points of low satisfaction have also been highlighted and warrant close observation and remediation. Establishing a longitudinal assessment of KAUDH quality of services assessed by patients' perceptions is needed to establish new strategies for improvements to patient care services.

\section{Limitations and Recommendations}

One of the main limitations of this study was that the questionnaire was only briefly validated for content by a panel of experts in the PCQA committee, based mostly on experience. A thorough validation process may be started in order to establish the questionnaire as a validated instrument to be used regularly and possibly by other local institutes. KAUFD needs to re-visit and improve the strategy for evaluating performance, particularly since it is expanding as an institute in terms of number of dental clinics. The plan should contain calculated guidelines (such as clear standards for care) for each department to follow, by which they can systematically measure their compliance levels. Regular reporting and feedback mechanisms are vital to improvement. Such mechanisms must be mandated and involve the Head of Department and the Board of Directors in order to monitor the levels of performance, help in understanding how the organization is performing, and how it can operate better in the future.

\section{Conflict of Interests}

The authors declare that there is no conflict of interest regarding the publication of this paper.

\section{Disclosure}

None of the authors received any type of commercial support either in forms of compensation or financial for this study. They have no financial interest in any of the products or devices, or drugs mentioned in this article.

\section{Ethical Approval}

Obtained.

\section{References}

[1] Bedi R, Gulati N, McGrath C. A study of satisfaction with dental services among adults in the United Kingdom. Br Dent J 2005; 198(7): 433-437.

[2] Chu CH, Lo EC. Patients' satisfaction with dental services provided by a university in Hong Kong. Int Dent J 1999; 49(1): 53-59.

[3] Hall E. Patient satisfaction-why should we care? AAEM 2010; 17(6): 17.

[4] Kurpas D, Steciwko A. Patient satisfaction as the main indicator of primary care quality. Przegl Lek 2005; 62(12): 1546-1551.

[5] Pascoe GC. Patient satisfaction in primary health care: a literature review and analysis. Eval Program Plann 1983; 6(3-4): 185-210.

[6] Westbrook Jl. Patient satisfaction: methodological issues and research findings. Aust Health Rev 1993; 16(1): 75-88.

[7] Brennan PF. Patient satisfaction and normative decision theory. J Am Med Inform Assoc 1995; 2(4): 250-259.

[8] Cole A. Patients' satisfaction with the NHS is growing, survey shows. BMJ 2006; 332(7553): 1292.

[9] Rubin HR, Gandek B, Rogers WH, Kosinski M, McHorney CA, 
Ware JE Jr. Patients' ratings of outpatient visits in different practice settings. Results from the Medical Outcomes Study. JAMA 1993; 270(7): 835-840.

[10] Landon BE, Zaslavsky AM, Bernard SL, Cioffi MJ, Cleary PD. Comparison of performance of traditional Medicare vs Medicare managed care. JAMA 2004; 291(14): 1744-1752.

[11] Raftopoulos $V$. A grounded theory for patients' satisfaction with quality of hospital care. ICUS Nurs 2005; 22: 1-15.

[12] Barbosa CD, Balp MM, Kulich K, Germain N, Rofail D. A literature review to explore the link between treatment satisfaction and adherence, compliance, and persistence. Patient Prefer Adherence 2012; 6: 39-48.

[13] Schoen C, Osborn R, Doty MM, Bishop M, Peugh J, Murukutla N. Toward higher-performance health systems: adults' health care experiences in seven countries, 2007. Health Aff (Milwood) 2007; 26(6): 717-734.

[14] Mclver S. An introduction to obtaining the views of the users of health services. $1^{\text {st }}$ edition. London: Baily Distribution Ltd., 1991. 2-10.

[15] Murray BP, Wiese HJ. Satisfaction with care and the utilization of dental services at a neighborhood health center. J Public Health Dent 1975; 35(03): 170-176.

[16] Ventä I, Murtomaa H, Meurman J, Turtola L. Use of dental services by students of Helsinki University during six years. Proc Finn Dent Soc 1992; 88(3-4): 123-129.

[17] Alaiban KM, Al-Omar B, Narine L, Al-Assaf AF, Javed F. A survey assessing patient satisfaction at public and private healthcare facilities in Riyadh, Saudi Arabia. Ann Saudi Med 2003; 23(6): 417-419.

[18] Al-Doghaither. Inpatient satisfaction with physician services at King Khalid University Hospital, Riyadh, Saudi Arabia. East Mediterr Health J 2004; 10(3): 258-264.

[19] Mahrous MS, Hinawy T. Patient satisfaction from dental services provided by the College of Dentistry, Taibah University, Saudi Arabia. J Taibah Uni Med Sci 2012; 7(2): 104-109.

[20] Mansour AA, al-Osimy MH. A study of satisfaction among primary health care patients in Saudi Arabia. J Community Health 1993; 18(3): 163-173.

[21] Al-Faris EA, KhojaT, Falouda M, Saeed A. Patients'satisfaction with accessibility and services offered in Riyadh health centers. Saudi Med J 1996; 17(1): 11-17.

[22] Saeed AA, Mohammed BA, Magzoub ME, Al-Doghaither AH. Satisfaction and correlates of patients' satisfaction with physicians' services in primary health care centers. Saudi Med J 2001; 22(3): 262-267.

[23] Awliya WY. Patient satisfaction with the dental services provided by the Dental College of King Saud University. Saudi Dent J 2003; 15(1): 11-16.

[24] Aldebasi YH, Ahmed IM. Patients' satisfaction with medical services in the Qassim area. J Clin Diagn Res 2011; 5(4): 813-817.

[25] Al-Refeidi A, Haralur SB, Odusanya SA, Elagib MF, Luqman
M. Patient satisfaction with the dental services of an educational institution. Int J Dent Clin 2012; 4(4): 1-5.

[26] Ginsburg JA, Doherty RB, Ralston JF Jr, Senkeeto N, Cooke M, Cutler C, Fleming DA, Freeman BP, Gluckman RA, Liebow M, LCLean RM, Musana KA, Nichols PM, Purtle MW, Reynolds PP, Weaver KM, Dale DC, Levine JS, Stubbs JW. Achieving a high-performance health care system with universal access: what the United States can learn from other countries. Ann Intern Med 2008; 148(1): 55-75.

[27] Ali M el-S, Mahmoud ME. A study of patient satisfaction with primary health care services in Saudi Arabia. J Community Health 1993; 18(1): 49-54.

[28] Holmes-Rovner M, Kroll J, Schmitt N, Rovner DR, Breer ML, Rothert ML, Padonu G, Talarczyk G. Patient satisfaction with health care decisions: the satisfaction with decision scale. Med Decis Making 1996; 16(1): 58-64.

[29] Humphries GM, Cooper CL. New stressors for GDPs in the past ten years: a qualitative study. Br Dent J 1998; 185(8): 404-406.

[30] Crossley ML, Blinkhorn A, Cox M. 'What do our patients really want from us?': Investigating patients perceptions of the validity of the Chartermark criteria. Br Dent J 2001; 190(11): 602-606.

[31] Shugars DA, DiMatteo MR, Hays RD, Cretin S, Johnson JD. Professional satisfaction among California general dentists. J Dent Educ 1990; 54(11): 661-669. 


\section{رضى المرضى عن الخدمات في مستشفى الاسنان بجامعة الملك عبد العزيز}

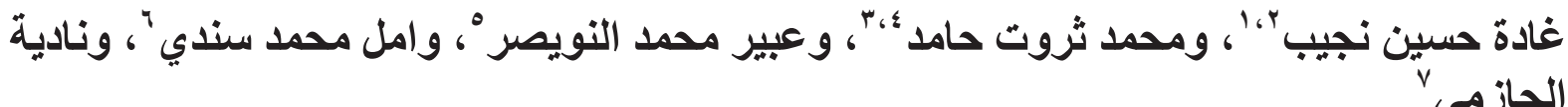

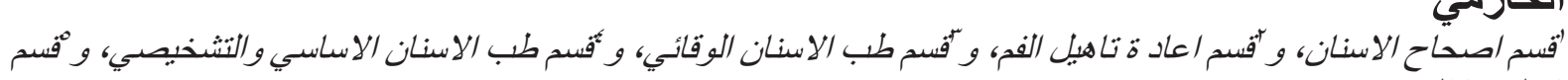

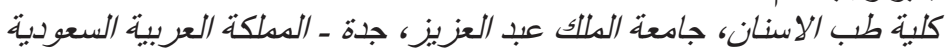

$$
\begin{aligned}
& \text { "قآسم بايولو جيا الفم ، "قفس التيجان و الجسور كلية طب الفم و الاسنان - جامعة القاهرة }
\end{aligned}
$$

العستخلص. ان مستوى رضى المريض في اي معهد صحي هو مفتاح مقياس الأداء لجودة العناية الصحية. لقد أنثأنا

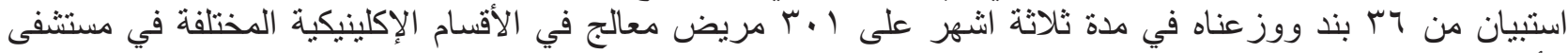

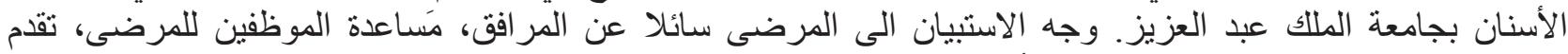

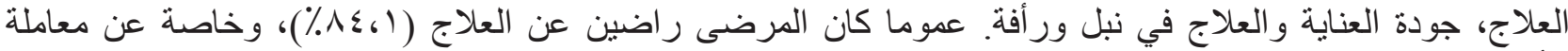

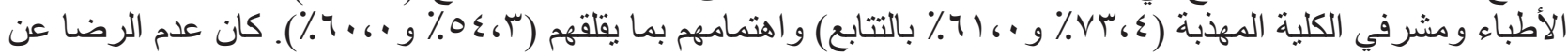

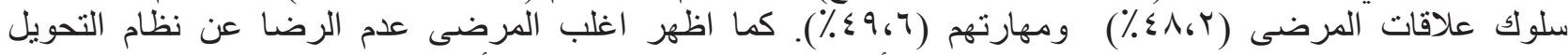

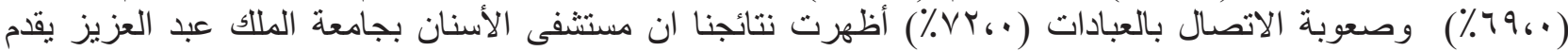

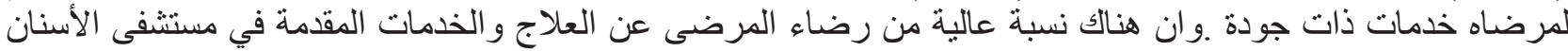
بجامعة الملك عبد العزيز. مع ذلك ماز الت هناك نقاط يجب ان نوض توخذ في الاعتبارلتحسين خدمة المريض. 